\title{
CORRECTION
}

\section{COVID-19 Among Patients With Multiple Sclerosis}

\section{A Systematic Review}

Neurol Neuroimmunol Neuroinflamm 2021;8:e1050. doi:10.1212/NXI.0000000000001050

In the Views and Reviews article "COVID-19 Among Patients With Multiple Sclerosis: A Systematic Review" by Barzegar et al., " the third author should be listed as "Mahsa Ghajarzadeh.” The authors regret the error.

\section{Reference}

1. Barzegar M, Mirmosayyeb O, Gajarzadeh M, et al. COVID-19 among patients with multiple sclerosis: a systematic review. Neurol Neuroimmunol Neuroinflamm 2021;8(4):e1001. doi: 10.1212/NXI.0000000000001001. 


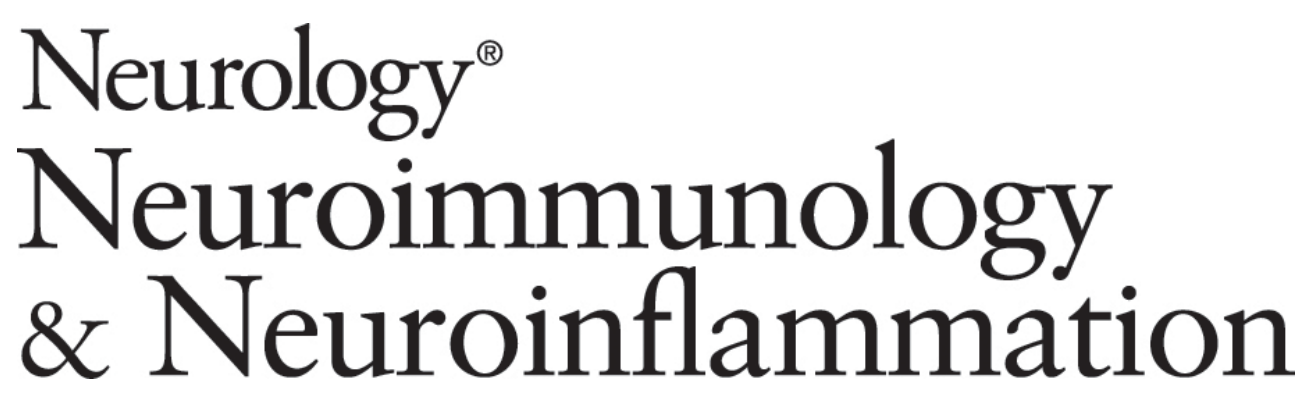
COVID-19 Among Patients With Multiple Sclerosis: A Systematic Review Neurol Neuroimmunol Neuroinflamm 2021;8;
DOI 10.1212/NXI.0000000000001050

This information is current as of July 2, 2021

$\begin{array}{ll}\begin{array}{l}\text { Updated Information \& } \\ \text { Services }\end{array} & \begin{array}{l}\text { including high resolution figures, can be found at: } \\ \text { http://nn.neurology.org/content/8/5/e1050.full.html }\end{array} \\ \text { References } & \begin{array}{l}\text { This article cites } 1 \text { articles, } 1 \text { of which you can access for } \\ \text { http://nn.neurology.org/content/8/5/e1050.full.html\#\#ref- }\end{array} \\ \text { Permissions \& Licensing } & \begin{array}{l}\text { Information about reproducing this article in parts (figures, } \\ \text { its entirety can be found online at: } \\ \text { http://nn.neurology.org/misc/about.xhtml\#permissions } \\ \text { Information about ordering reprints can be found online: } \\ \text { http://nn.neurology.org/misc/addir.xhtml\#reprintsus }\end{array}\end{array}$

Neurol Neuroimmunol Neuroinflamm is an official journal of the American Academy of Neurology.

Published since April 2014, it is an open-access, online-only, continuous publication journal. Copyright $\odot$ 2021 American Academy of Neurology. All rights reserved. Online ISSN: 2332-7812.

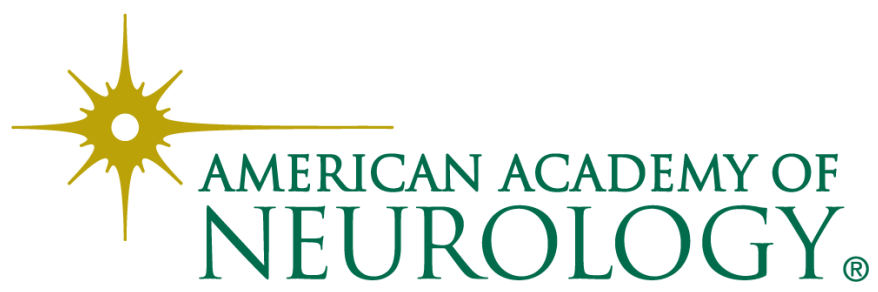

